\title{
MODELLING OVERWASH AND INFILTRATION ON GRAVEL BARRIERS
}

\author{
Robert McCall ${ }^{1,2}$, Gerd Masselink ${ }^{1}$, Dano Roelvink ${ }^{2,3}$, Paul Russel ${ }^{1}$, Mark Davidson ${ }^{1}$, Timothy \\ Poate $^{1}$
}

\begin{abstract}
A quasi-3D process-based and time dependent groundwater model is developed and coupled to a hydrodynamic storm impact model to simulate the effect of infiltration on overwash on a gravel barrier. The coupled model is shown to accurately reproduce groundwater variations, runup properties and overwash time series measured in the gravel barrier during a large-scale physical model experiment. The coupled model is applied to study the influence of hydraulic conductivity on overwash volumes. It is shown that modeled overwash volumes are significantly affected by infiltration for hydraulic conductivity values greater than $0.01 \mathrm{~ms}^{-1}$.
\end{abstract}

Keywords: gravel, barrier, overwash, infiltration, groundwater, modeling

\section{INTRODUCTION}

Gravel beaches and barriers occur on many high-latitude, wave-dominated coasts across the world. In the UK, gravel coasts are seen as a sustainable form of coastal defense, and gravel is routinely used to nourish the coast (Moses and Williams, 2009).

Despite much scientific work to describe gravel barrier response to extreme storm events in a qualitative sense (e.g., Orford, 1977), coastal managers are currently forced to rely on simple empirical models to make quantitative predictions of gravel beach storm response (e.g., Powell, 1990; Bradbury, 2000). Such empirical models have been applied with some success in the UK, but are inherently limited by the range of conditions and data from which they are derived. Process-based models offer an improvement over empirical models in that if the important underlying physics are understood, these models can be universally applied. Unfortunately for coastal managers few process-based models for gravel coasts exist, and where they do their focus is on mild wave conditions (e.g., Pedrozo-Acuña et al., 2006; Jamal et al., 2010).

In recent years progress has been made in the development of process-based models for storm impact on sandy coasts. The extension of these process-based models to application on gravel beaches requires understanding and incorporation of physics that are different to those on sandy beaches during storms. Such processes may include a dominance of swash zone and bedload sediment transport, rather than surf zone and suspended load transport; incident and sub-harmonic wave action, rather than infragravity wave action; wave run-up, rather than set-up; and morpho-sedimentary dynamics (Buscombe and Masselink, 2006). More importantly, most processed-based models for sandy coasts do not take into account the infiltration and exfiltration of surface water and groundwater. The interaction between surface water and groundwater is considered to play an important role in the morphology of gravel beaches (e.g., Mason, 2001; Jennings, 2002; Buscombe and Masselink, 2006). Infiltration during the uprush and start of backwash is generally considered to promote shoreward sediment transport in the swash by creating onshore swash asymmetry (e.g., Bagnold, 1940).

Although effect of the interaction between the groundwater and surface water during storm conditions has not been independently examined, it is reasonable to assume that infiltration will have significant influence on wave runup levels and overtopping volumes. In order to accurately model the hydrodynamics and morphodynamics on gravel barriers during storm events using a process-based model, we propose that it is necessary to include groundwater effects.

In this paper we attempt to improve our modeling capability for predicting gravel barrier response to extreme events through the coupling of an existing process-based model for sandy coasts, to a new nonhydrostatic groundwater model. This coupling allows the hydrodynamics above the bed (the surface water dynamics) to be computed by the existing nearshore model. Groundwater dynamics and

\footnotetext{
${ }_{1}^{1}$ School of Marine Science and Engineering, Plymouth University, Drake Circus, Plymouth, United Kingdom

${ }^{2}$ Deltares, Rotterdamseweg 185, Delft, The Netherlands

${ }^{3}$ UNESCO-IHE, Westvest 7, Delft, The Netherlands
} 
interaction between the surface water and the groundwater are computed by the new groundwater model. The coupled groundwater-surface water model is calibrated and validated using data from the BARDEX large-scale physical models experiment (Williams et al., 2012a). Since the morphodynamic processes in the surface water model have not yet been fully validated for gravel beaches, validation is carried out using only hydrodynamic data over short periods in which bed level change is negligible. We will first briefly describe the surface water model used in this study. We subsequently discuss the new groundwater model and the processes therein. In the second half of this paper, we discuss the calibration and validation of the coupled groundwater-surface water model, using the BARDEX dataset and end with a discussion of the implications of this study for gravel barrier modeling.

\section{SURFACE WATER MODEL DESCRIPTION}

In this paper we use an existing open-source, process-based morphodynamic model for the nearshore and coast called XBeach (Roelvink et al., 2009) to simulate surface water hydrodynamics on a gravel barrier. The XBeach model has been shown to have quantitative skill in hindcasting storm impact, overwash and breaching processes on sandy beaches (Roelvink et al., 2009; McCall et al., 2010). The model has shown promising results in early attempts to simulate morphology on gravel beaches (Williams et al., 2012b; Jamal et al., 2010).

The XBeach model has recently been extended to simulate non-hydrostatic flow (Smit et al, 2010), in a manner similar to the one-layer version of the SWASH model (Zijlema et al., 2011). This modification enables XBeach to solve waves up to $k h<\sim 2(\sim 2.5 \mathrm{~s}$ or greater wave period in this paper) to be solved accurately using the non-linear shallow water wave equations, combined with a pressure correction term. The momentum equations solved by XBeach assume incompressible, homogeneous and Newtonian flow and can be written in Cartesian coordinates as (Smit et al., 2010):

$$
\frac{\delta U}{\delta t}+\nabla(U \otimes U)=-\frac{1}{\rho} \nabla(p+\rho g \eta)+\nabla \cdot \tau
$$

Where $\boldsymbol{U}=[u(\boldsymbol{x}, t), v(\boldsymbol{x}, t), w(\boldsymbol{x}, t)]$ is the velocity vector, $p$ is the dynamic pressure normalized with the reference density $\rho, g$ the gravitational body force, $\eta$ the free surface elevation and $\tau$ represents the turbulent shear stress tensor. Conservation of mass is enforced by a non-divergent flow field:

$$
\nabla U=0
$$

In this paper, we allow for mass interaction between the surface water and groundwater. This interaction is taken into account by means of an additional term in the mass balance of the surface water, and is discussed in the following section.

\section{GROUNDWATER MODEL DESCRIPTION}

The principal components of the new groundwater model are shown in Figure 1. The model computes depth-averaged groundwater flows, as well as groundwater level and head fluctuations. Interaction with the surface water is handled through infiltration and exfiltration over unsaturated beds. In saturated beds, submarine exchange takes place due vertical head gradients, for which a non-hydrostatic groundwater modeling approach must be taken.

Although vertical variations in groundwater flow and complex groundwater circulation may play an important role in the transport of solutes, it is not expected to affect storm morphology on gravel barriers. Therefore a $2 \mathrm{DH}$ (or quasi-3D), rather than $3 \mathrm{D}$, modeling approach is considered sufficient to model the primary groundwater processes during storms. 


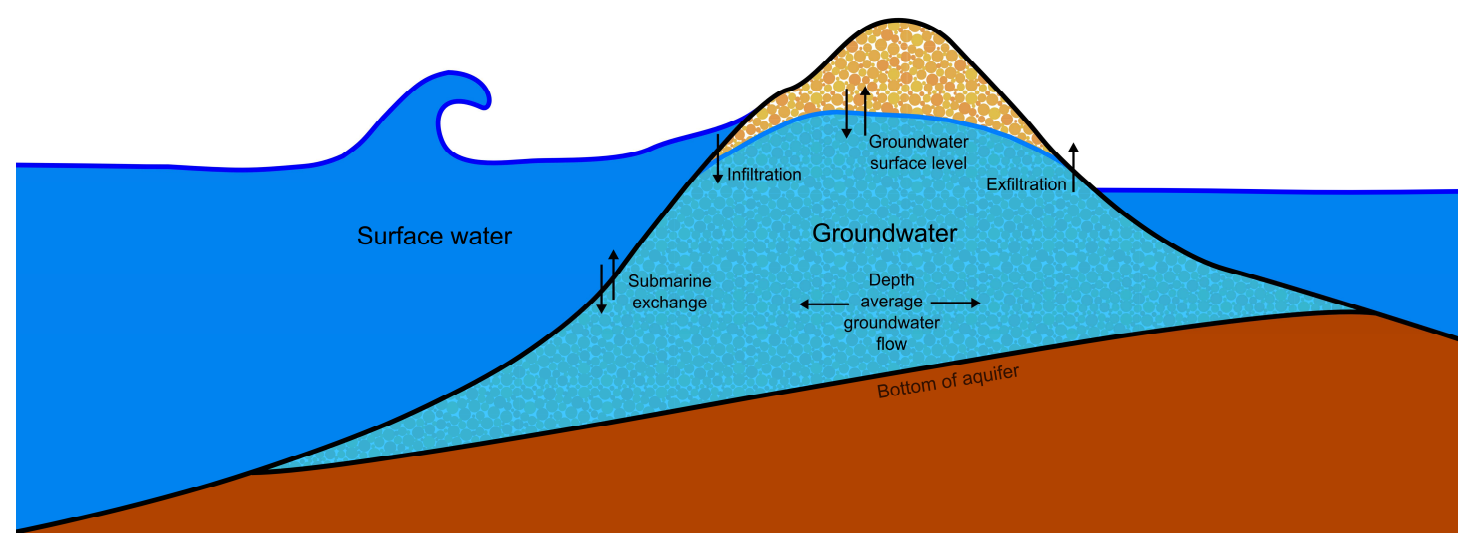

Figure 1. Principle components of groundwater flow model and interaction with surface water.

In order to solve mass continuity in the groundwater model, the groundwater is assumed to be incompressible. Continuity is achieved by imposing a non-divergent flow field:

$$
\nabla \vec{U}=0
$$

where $\vec{U}$ is the total specific discharge velocity vector, with components in the horizontal $(u, v)$ and vertical $(w)$ direction:

$$
\vec{U}=\left[\begin{array}{c}
u \\
v \\
w
\end{array}\right]
$$

Laminar flow of an incompressible fluid through a homogeneous medium can be described using the well-known Law of Darcy (1856):

$$
\nabla H=-\frac{1}{K} \vec{U}
$$

where $K$ is the hydraulic conductivity of the medium, and $H$ is the hydraulic head:

$$
H=z+\frac{p}{\rho g}
$$

In situations in which flow is not laminar, turbulent terms may become important, which can be incorporated by modification of the hydraulic conductivity:

$$
\nabla H=\frac{1}{K(a, b,|\vec{U}|)} \vec{U}
$$

where the laminar and turbulent hydraulic conductivity is a function of laminar and turbulent coefficients $a$ and $b$, and the absolute specific discharge velocity $(|\vec{U}|)$. Many empirical and semiempirical relations have been suggested for $a$ and $b$ (e.g. Ergun, 1952; Ward, 1964; and many others), but unfortunately no single relation has been shown to be valid for varying grain sizes without substantial calibration of coefficients. In addition, most relations give no practical guidance to users how to estimate the correct coefficients, other than to carry out laboratory experiments.

The groundwater model described in this paper uses the approach taken by the USGS MODFLOW2005 groundwater model (Harbaugh, 2005), in which the turbulent hydraulic conductivity is estimated based on the laminar hydraulic conductivity $\left(K_{\text {lam }}\right)$ and the Reynolds number at the start of turbulence $\left(R e_{c r i t}\right)$ (Halford, 2000; Kuniansky et al., 2008; Shoemaker et al., 2008):

$$
K=\left\{\begin{array}{cc}
K_{\text {lam }} \sqrt{\frac{R e_{\text {crit }}}{R e}} & R e>R e_{\text {crit }} \\
K_{\text {lam }} & R e \leq R e_{\text {crit }}
\end{array}\right.
$$


where the Reynolds number is calculated using the median grain size $\left(D_{50}\right)$, the kinematic viscosity of water $(v)$ and the groundwater velocity in the pores $(U / n)$, where $n$ is the porosity:

$$
\operatorname{Re}=\frac{|U| D_{50}}{n v}
$$

Since the hydraulic conductivity in the turbulent regime is dependent on the local velocity, an iterative approach is taken to find the correct hydraulic conductivity and velocity.

\section{Vertical groundwater head approximation}

Since the groundwater model is depth-averaged, the model cannot compute true vertical profiles of the groundwater head and velocity. In order to improve the estimate of the groundwater head variation over the vertical, a quasi-3D modeling approach is applied. In this approach the groundwater head is estimated by a curve in the vertical (see Figure 2), which is set by three conditions:

1. There is no exchange of groundwater between the aquifer and the impermeable layer below the aquifer. Therefore the vertical velocity at the bottom of the aquifer $(z=0)$ and the vertical head gradient at the bottom of the aquifer are zero:

$$
w(0)=\left.0 \rightarrow \frac{\partial H}{\partial z}\right|^{z=0}=0
$$

2. The groundwater head at the upper surface of the groundwater $(z=\eta)$ is continuous with the head applied at the surface:

$$
H(\eta)=H_{\eta}
$$

3. The vertical velocity is assumed to increase or decrease linearly from the bottom of the aquifer to the upper surface of the groundwater:

$$
w(z)=\alpha z \rightarrow \frac{\partial^{2} H}{\partial z^{2}}=\alpha
$$

where $\alpha$ is an arbitrary constant.

Points 1 and 2 in the previous follow strictly from the conditions imposed on the entire groundwater model and are therefore valid within the modeling approach. However, point 3 is an assumption that may not be valid in all situations and is a limitation of this approach. The error associated with the assumption made in point 3 is considered preferable to the computational cost of a fully threedimensional groundwater modeling approach.

The vertical groundwater head approximation can be solved for the three conditions imposed by a parabolic function:

$$
H(z)=\beta z^{2}+H_{\eta}-\beta \eta^{2}
$$

in which $z$ is the vertical coordinate above the bottom of the aquifer, $\eta$ is the level of the groundwater surface above the bottom of the aquifer, $\beta$ is the curvature coefficient and $H_{\eta}$ is the head imposed at the groundwater surface. In the case of hydrostatic pressure, $\beta$ reduces to zero.

The depth-average value of the groundwater head is used to calculate the horizontal groundwater flux and is found by integrating the groundwater head approximation (Eq. 13) over the vertical:

$$
\bar{H}=\frac{1}{\eta} \int_{0}^{\eta} H(z) d z=H_{\eta}-\frac{2}{3} \beta \eta^{2}
$$




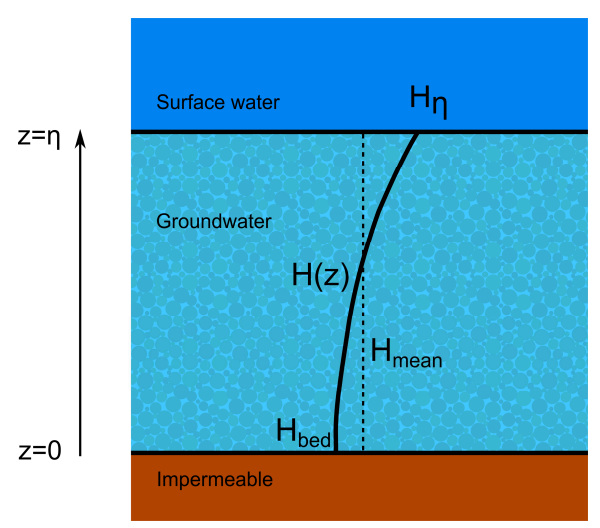

Figure 2. Schematic representation of quasi-3D groundwater head approximation.

\section{Exchange with surface water}

In the groundwater model there are three mechanisms for the exchange of groundwater and surface water: submarine exchange, infiltration and exfiltration (see Figure 1). The rate of exchange between the groundwater and surface water $(S)$ is given in terms surface water volume, and is defined positive when water is exchanged from the surface water to the groundwater.

The groundwater and surface water are said to be in a connected state where and when the groundwater level reaches to the top of the bed and surface water exists above the bed. This state is described by a spatially and temporally varying logical $C$, which is true where groundwater and surface water are connected and false in all other situations:

$$
C= \begin{cases}\text { true } & \eta_{g w} \geq z_{\text {bed }} \wedge \eta_{\text {sw }} \geq z_{\text {bed }} \\ \text { false } & \eta_{\text {gw }}<z_{\text {bed }} \vee \eta_{\text {sw }}<z_{\text {bed }}\end{cases}
$$

where $\eta_{g w}$ is the groundwater surface level, $\eta_{s w}$ is the surface water level and $z_{b e d}$ is the bed level.

Submarine exchange represents the high and low frequency infiltration and exfiltration through the bed due pressure gradients across the bed. This process only takes place where the groundwater and surface water are connected. The rate of submarine exchange is determined by the vertical specific discharge velocity at the interface between the groundwater and surface water. The value of this velocity can be found using the vertical derivative of the approximated groundwater head (Eq. 13) at the groundwater surface water interface:

$$
S=-w\left(\eta_{g w}\right)=\left.K \frac{\partial H}{\partial z}\right|^{z=\eta_{g v}}=2 \beta \eta_{g w} K
$$

Infiltration and exfiltration can occur in locations where the groundwater and surface water are not connected (see Figure 1). Infiltration takes place when surface water covers an area in which the groundwater level is lower than the bed level, i.e. an unsaturated bed. The flux of surface water into the bed is related to the pressure gradient across the wetting front in a manner similar to the approach taken by Packwood (1983):

$$
S=K\left(\frac{1}{\rho g} \frac{p_{s w}\left(z_{b e d}\right)}{d_{\text {infli }}}+1\right)
$$

where $p_{s w}\left(z_{b e d}\right)$ is the surface water pressure at the bed and $d_{i n f i l}$ is the thickness of the wetting front.

The thickness of the wetting front increases over time during the infiltration event according to the infiltration velocity:

$$
d_{\text {infil }}(t)=\int \frac{S}{n} d t
$$

Since the groundwater model is depth-averaged and cannot track multiple layers of groundwater infiltrating into the bed, the wetting front thickness is reset to zero when there is no available surface 
water, the groundwater exceeds the surface of the bed, or the groundwater and the surface water become connected. In addition, all infiltrating surface water is instantaneously added to the groundwater volume, independent of the distance from the bed to the groundwater table.

Exfiltration occurs where the groundwater and surface water are not connected and the groundwater level exceeds the bed level. The rate of exfiltration is related to the rate of the groundwater level exceeding the bed level:

$$
S=n \frac{\partial\left(z_{b e d}-\eta_{g w}\right)}{\partial t}
$$

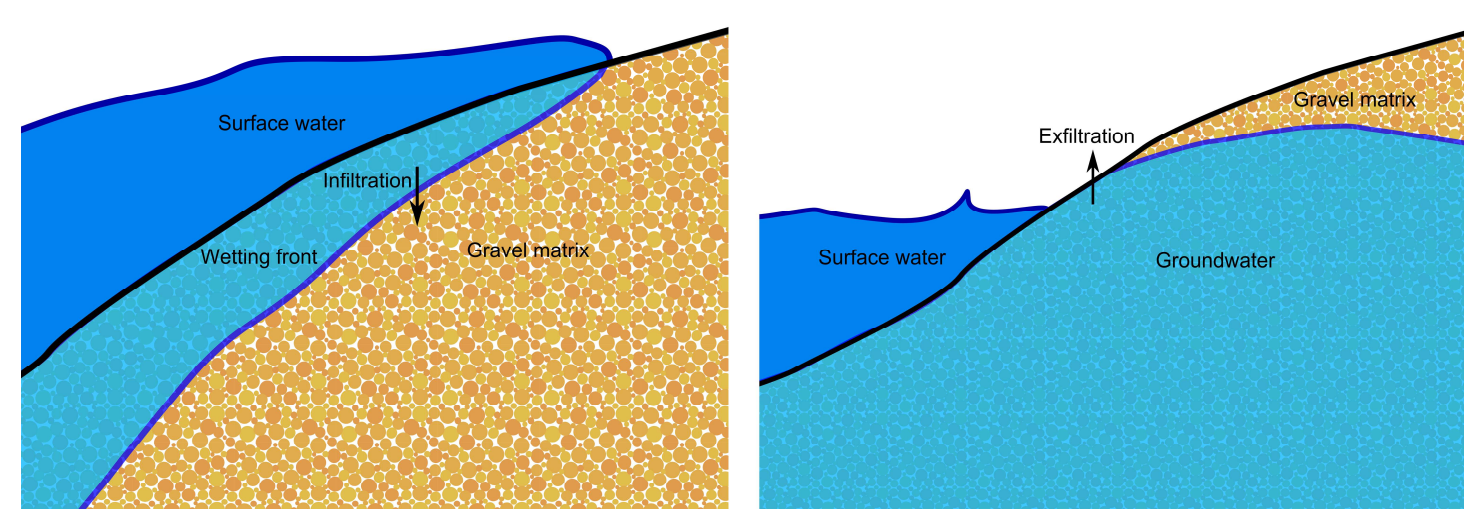

Figure 3. Schematic example of infiltration during a swash event (left panel) and exfiltration due to a high groundwater table (right panel).

\section{Calculation of groundwater and surface water levels}

The curvature coefficient $(\beta)$ in the vertical groundwater head approximation is solved using the coupled equations for continuity and motion (Eqs. 3 and 7), thereby producing the depth-average horizontal groundwater head gradients and vertical head gradients at the groundwater surface, and subsequent depth-average horizontal and vertical specific discharge. In areas where the groundwater and surface water are not connected, the groundwater level change is related to the vertical specific discharge and the infiltration and exfiltration fluxes:

$$
n \frac{\partial \eta_{g w}}{\partial t}=w+S_{i n f i l}+S_{e x f i l}
$$

In these same areas the surface water level is modified to account for infiltration and exfiltration:

$$
\frac{\partial \eta_{s w}}{\partial t}=-\left(S_{i n f i l}+S_{e x f i l}\right)
$$

In areas where the groundwater and surface water are connected, the groundwater level is set to remain at the level of the bed. The surface water level is modified to account for the submarine exchange with the groundwater:

$$
\begin{gathered}
\frac{\partial \eta_{g w}}{\partial t}=0 \\
\frac{\partial \eta_{s w}}{\partial t}=-S_{\text {submarine }}
\end{gathered}
$$

In cases where there is not sufficient surface water to permeate into the bed to ensure the groundwater level remains at the bed level, a fractional time step approach is taken in which the area is considered to be connected while there is sufficient surface water, and considered unconnected once the surface water has drained away. A similar approach is taken when the groundwater level reaches the bed level during an infiltration event. 


\section{VALIDATION DATASET}

The coupled surface water and groundwater model is calibrated and validated using hydrodynamic data measured during the Barrier Dynamics Experiment (BARDEX; Williams et al., 2012a) in the Delta Flume, The Netherlands. During the BARDEX physical model experiment, the hydrodynamics and morphodynamics of a 4 meter high and 50 meter wide gravel barrier under varying tidal and wave forcing conditions were measured by an array of instruments.

In this paper we use the hydrodynamic data of one subseries of the BARDEX experiment without waves (series C6equi, see Table 1) to calibrate the groundwater model. The coupled surface water and groundwater model is subsequently validated using four 10-minute subseries of the BARDEX experiment which include waves, runup and overwash (BB1, C1, C2 and E10).

Modeled groundwater hydrodynamics are compared to the groundwater head measured at 15 pressure transducers buried in the bed beneath the gravel barrier (triangles in Figure 4). Modeled surface water hydrodynamics are calibrated using water surface elevation time series measured by three offshore wave gauges (circles in Figure 4). Validation of the surface water hydrodynamics is carried out using data provided by a shallow water pressure transducer and 45 ultrasonic bed level sensors (square and dots respectively in Figure 4).

\begin{tabular}{|c|c|c|c|c|}
\hline \multicolumn{6}{|c|}{ Table 1. Wave and tide forcing conditions for BARDEX subseries } \\
\hline Series & $\begin{array}{c}\text { Offshore water } \\
\text { level }(\mathrm{m})\end{array}$ & $\begin{array}{c}\text { Lagoon water } \\
\text { level }(\mathrm{m})\end{array}$ & $\begin{array}{c}\text { Significant wave } \\
\text { height }(\mathrm{m})\end{array}$ & $\begin{array}{c}\text { Peak wave } \\
\text { period }(\mathrm{s})\end{array}$ \\
\hline C6equi & $2.6-2.9$ & $3.6-3.0$ & - & - \\
BB1 & 2.5 & 2.5 & 0.8 & 4.5 \\
C1 & 2.5 & 1.0 & 0.8 & 4.5 \\
C2 & 2.5 & 3.5 & 0.8 & 4.5 \\
E10 & 3.7 & 3.2 & 0.8 & 7.7 \\
\hline
\end{tabular}

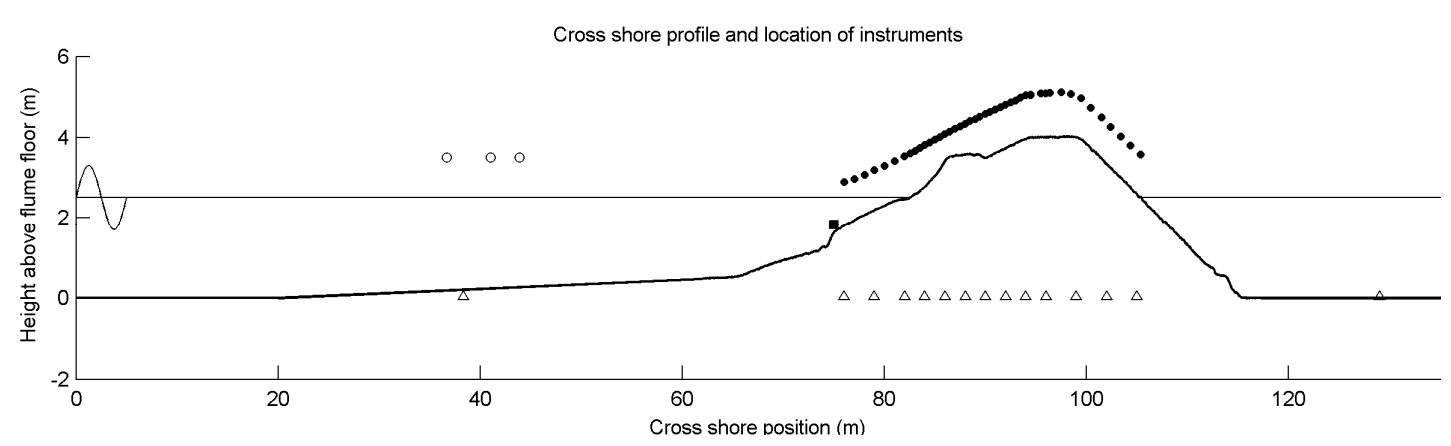

Figure 4. Representative water level and cross shore profile of the BARDEX gravel barrier. Instrument locations are shown for series BB1: offshore wave gauges (circles), shallow water pressure transducer (square), ultrasonic bed level sensors (dots) and buried pressure transducers (triangles).

Where modeled hydrodynamics are compared to measured hydrodynamics in this paper, the model accuracy is expressed in terms of the root-mean-square error (RMSE) and bias as defined below:

$$
\begin{aligned}
R M S E & =\sqrt{\frac{1}{N} \sum^{N}\left(x_{\text {modeled }}-x_{\text {measured }}\right)^{2}} \\
\text { bias } & =\frac{1}{N} \sum^{N}\left(x_{\text {modeled }}-x_{\text {measured }}\right)
\end{aligned}
$$

where $x$ is the variable for which the accuracy is being computed, and $N$ is the length of the data series.

The skill of a model (often referred to as the Brier Skill Score) can be described by the increase in the accuracy of the model relative to the accuracy of another existing model or best-estimate: 


$$
\text { skill }=1-\frac{\frac{1}{N} \sum^{N}\left(x_{\text {modelled }}-x_{\text {measured }}\right)^{2}}{\frac{1}{N} \sum^{N}\left(x_{\text {estimated }}-x_{\text {measured }}\right)^{2}}
$$

Positive skill scores imply that the model is an improvement over the estimate. A skill scores of 1 implies perfect model agreement, whereas a skill scores of, for instance, 0.9 implies that the variance of the model error is only $10 \%$ of the variance of the error of the estimate. A skill score of zero indicates that the model and estimate are of equal accuracy and negative skill scores imply that the model is a worsening over the estimate.

\section{GROUNDWATER MODEL CALIBRATION}

To calibrate the groundwater model a subseries of the BARDEX dataset without waves is selected in which groundwater levels vary spatially and temporally. The period selected for this calibration is subseries C6equi, in which an initially large gradient in the water level across the barrier (sea level = $2.6 \mathrm{~m}$; lagoon level $=3.5 \mathrm{~m}$ ) equilibrates over the period of approximately an hour by means of groundwater flow through the barrier (sea and lagoon level $=2.9 \mathrm{~m}$ ).

Multiple simulations of series C6equi are run in which the uniform hydraulic conductivity $\left(K_{\text {lam }}\right)$ and critical Reynolds number $\left(R e_{c r i t}\right)$ are varied independently within ranges found experimentally during the BARDEX experiment by Turner and Masselink (2012) and proposed by Shoemaker et al. (2008), see Table 2. In all calibration simulations, the water level on the lagoon boundary (cross-shore location $137 \mathrm{~m}$ ) is forced using the measured water level in the lagoon. A wall boundary condition is imposed on the offshore boundary (cross-shore location $0 \mathrm{~m}$ ). The envelope of the groundwater head simulated during all calibration simulations is shown in Figure 5 (light grey) for four locations under the gravel barrier.

The accuracy of every calibration simulation is determined by the combined RMSE of the simulated groundwater head time series at all buried pressure transducers under the gravel barrier (PT1-PT13). The calibrated values of the hydraulic conductivity and critical Reynolds number are determined by the simulation with the lowest combined RMSE. These values are found to be 75 for the critical Reynolds number and $0.19 \mathrm{~ms}^{-1}$ for the hydraulic conductivity (Table 2), which corresponds well with the values of hydraulic conductivity (range $0.1-0.3 \mathrm{~ms}^{-1}$; mean $0.16 \mathrm{~ms}^{-1}$ ) found by Turner and Masselink (2012).

The results of the simulation of C6equi using the calibrated model parameters are shown in Figure 5 (red dashed). The RMSE and absolute bias at every buried pressure transducer using the calibrated model is shown to be less than $0.02 \mathrm{~m}$ (Table 3 ). The skill of the groundwater model relative to an estimate of zero groundwater head change (i.e., no groundwater dynamics) is very high, emphasizing the importance of including groundwater dynamics.
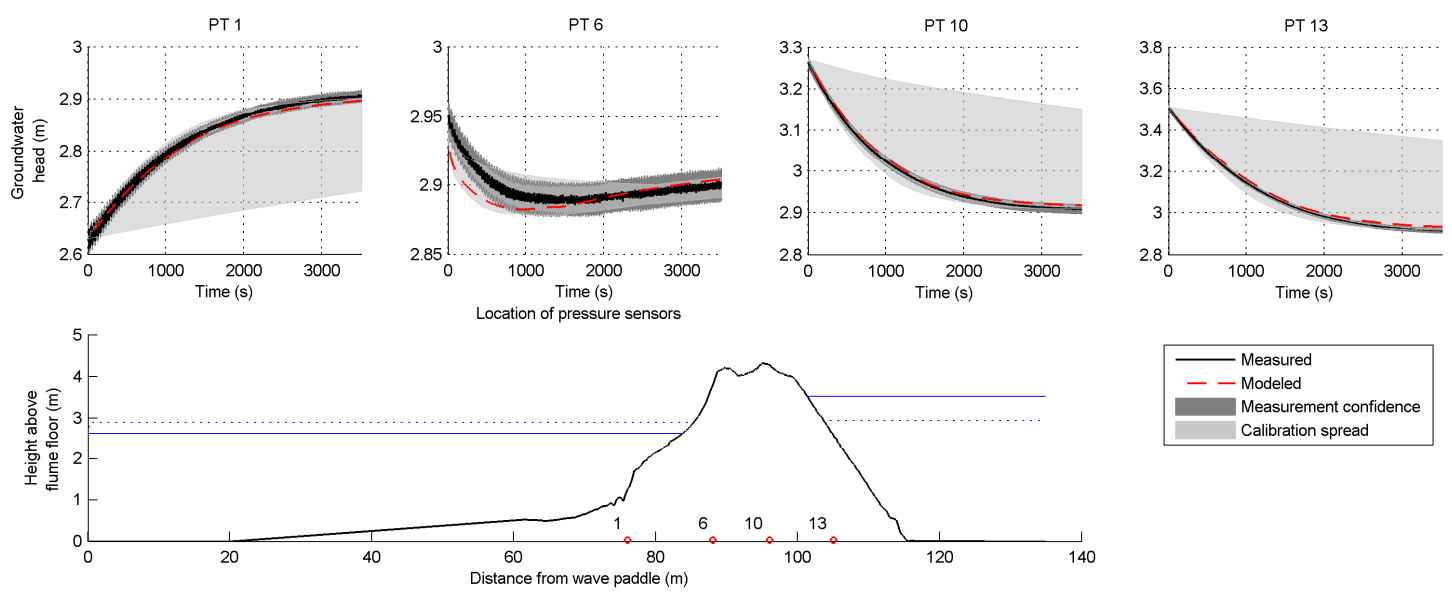

Figure 5. Time series of measured (black) and simulated (red dashed) groundwater head at four locations in the gravel barrier using the calibrated model. The spread in model results for the entire range of parameter settings is shown in light grey. 


\begin{tabular}{|c|cc|}
\hline \multicolumn{3}{|c|}{ Table 2. Parameter calibration range and best-fit calibration value for the groundwater model } \\
\hline Parameter & Parameter calibration range & Calibrated value \\
\hline$K_{\text {lam }}$ & $0.10 \mathrm{~ms}^{-1}-0.30 \mathrm{~ms}^{-1}$ & $0.19 \mathrm{~ms}^{-1}$ \\
$\operatorname{Re}_{\text {crit }}$ & $1-100$ & 75 \\
\hline
\end{tabular}

\begin{tabular}{|c|c|c|c|}
\hline & RMSE (m) & Bias (m) & Skill (-) \\
\hline Maximum PT1-PT13 & 0.02 & -0.02 & 0.99 \\
\hline Median PT1-PT13 & 0.01 & $<0.01$ & 0.99 \\
\hline Minimum PT1-PT13 & $<0.01$ & $<0.01$ & 0.68 \\
\hline
\end{tabular}

\section{COUPLED MODEL VALIDATION}

The coupled groundwater-surface water model is validated using three subseries of the BARDEX dataset in which wave motions were limited to runup on the beachface (series BB1, C1 and C2), and one subseries in which overtopping and overwash took place (series E10). Since the models used in this study do not contain morphodynamic updating for gravel beds, all simulations are limited to 10 minutes, during which the bed profile is assumed to be quasi-stationary.

In all validation cases, the offshore boundary is forced using the incident wave elevation time series that was measured by the Delta Flume wave generator (cross-shore location 0m). Linear wave theory and bound higher and lower harmonics are used to generate the associated time series of incident depthaveraged velocity. The total incident signal is scaled by up to $15 \%$ to ensure the modeled wave energy at the center wave gauge (cross-shore location $41 \mathrm{~m}$ ) matches the measured wave energy at that location. The lagoon boundary is forced using measured water levels only. Wave-absorbing boundary conditions are imposed on the offshore and bay-side boundary to minimize reflection of waves at the model boundaries.

All simulations use the calibrated coefficients for hydraulic conductivity and start of turbulence described in the previous section. The Chézy bed friction factor in all simulations is set to $37 \mathrm{~m}^{1 / 2} \mathrm{~s}^{-1}$, based on typical values for gravel bed rivers (e.g. CIRIA et al., 2007). The cross-shore numerical grid resolution in all models varies from $0.25 \mathrm{~m}$ in deep water to $0.05 \mathrm{~m}$ at the barrier.

\section{Runup simulations}

Three subseries of the BARDEX dataset with similar waves, but varying groundwater gradients across the barrier, are simulated using the coupled groundwater-surface water model. These simulations are characterized by equal offshore and lagoon water levels (BB1), a low lagoon water level (C1) and a high lagoon water level (C2), see Table 1.

Figure 6 shows the measured and modeled surface water elevation spectra at the location of the shallow water pressure transducer (cross-shore location $75 \mathrm{~m}$ ). The figure shows that the coupled model is capable of accurately reproducing the hydraulic conditions at the start of the gravel profile and can confidently be used to predict runup on the beach face.

The measured and modeled groundwater head time series at four locations in the gravel barrier for all three runup simulations are shown in Figure 7. The figure shows that the coupled groundwater-surface water model can reproduce the measured groundwater dynamics on the offshore side of gravel barrier (PT1 and PT6) relatively well in all three simulations. In particular, the model is able to capture the shift from high-frequency variance at PT1 to low-frequency variance at PT6 well. On the back-barrier (PT10 and PT13), Series BB1 and C2 are reproduced well, but the model suffers from an over prediction of the groundwater head in Series C1 (low lagoon water level). This over-prediction may be due to the limitations of the quasi-3D approximation of the groundwater head, in combination with the highly non-hydrostatic pressures in the barrier caused by a very steep water level gradient across the barrier. Alternatively, spatial variations of the hydraulic conductivity of the barrier, which are not accounted for in the model, may lead to larger variations in the groundwater head than predicted in the model. 
Overall, the groundwater model is capable of reproducing the measured groundwater head time series at all buried pressure transducers in the gravel barrier with a median RMS error of $0.03 \mathrm{~m}$ to $0.09 \mathrm{~m}$ (Table 4), which is approximately 1-5 times larger than the estimated accuracy of the measurements. Most importantly, the groundwater model shows clear skill over an estimate of zero groundwater head change.

Figure 8 and Table 5 show measured (white) and modeled (black) runup height data for all three simulations. In this analysis, measured runup height data are determined from individual swash depth time series measured by the array of 45 ultrasonic bed level sensors (cf., Turner et al., 2008). Modeled runup data are extracted in a similar manner from the modeled swash depth dataset. The results show that in general, the coupled groundwater-surface water model reproduces the distribution of runup heights relatively well. In particular, they show that the model is capable of predicting the $2 \%$ exceedence runup height $\left(R_{2 \%}\right)$ with an error of less than 3\%. Note that the higher runup levels (measured and modeled) in Series $\mathrm{C} 1$ are principally due to a steeper beach face in that series, rather than due to groundwater effects.

The effect of coupling the groundwater model to the surface water model on the predicted runup levels is analyzed by re-simulating the same periods with only the surface water model, and no interaction with groundwater. The data of these simulations (Table 5 and grey in Figure 8) show that the inclusion of the groundwater model is essential in correctly predicting the maximum runup height.
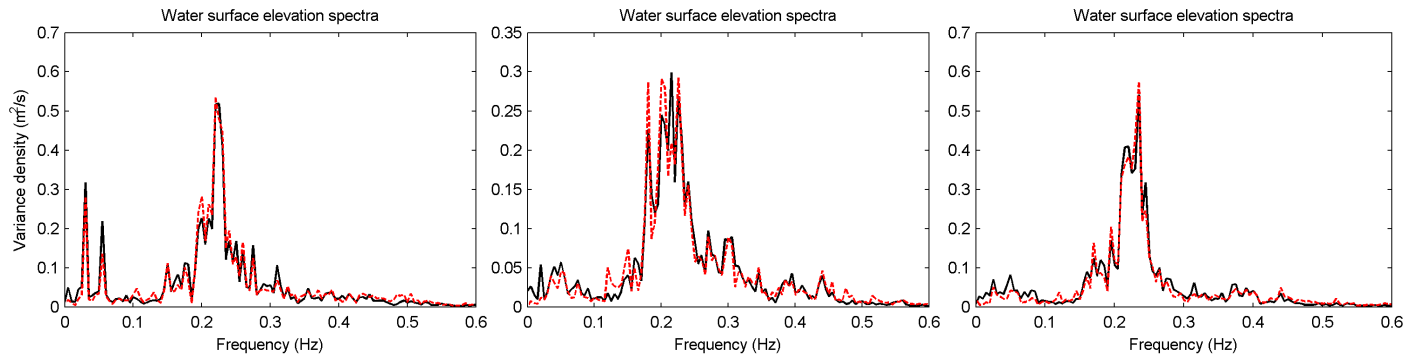

Figure 6. Measured (black) and modeled (red dashed) surface water elevation spectra at the location of the shallow water pressure transducer (cross-shore location $75 \mathrm{~m}$ ) for Series BB1 (left), C1 (center) and C2 (right).
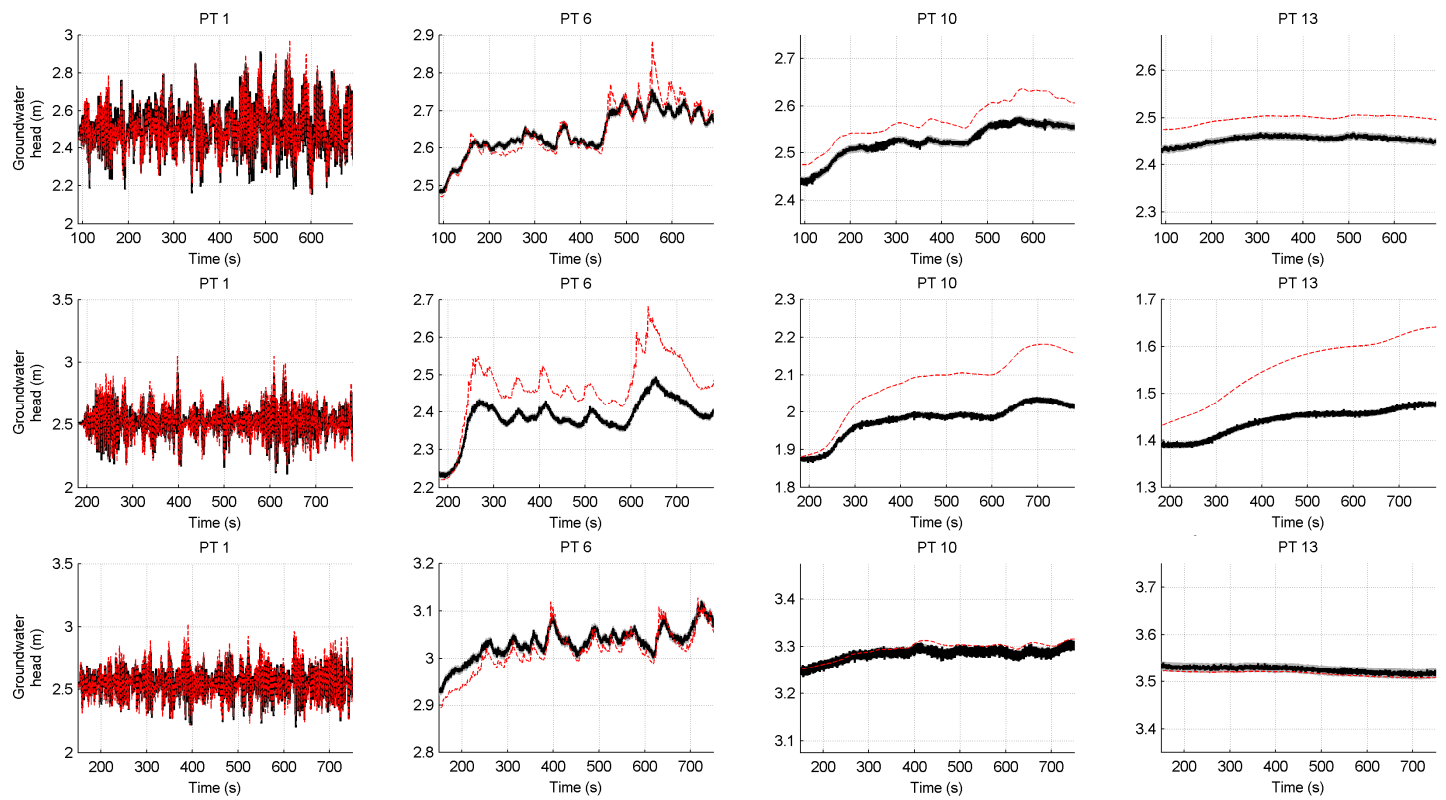

Figure 7. Measured (black) and modeled (red dashed) time series of groundwater head at four locations in the gravel barrier, during series BB1 (top row), C1 (center row) and C2 (bottom row). Note that all locations correspond to those shown in Figure 5. 


\begin{tabular}{|c|c|c|c|c|c|c|c|c|c|}
\hline & \multicolumn{3}{|c|}{ BB1 } & \multicolumn{3}{|c|}{$\mathrm{C} 1$} & \multicolumn{3}{|c|}{$\mathrm{C} 2$} \\
\hline & RMSE (m) & Bias (m) & Skill (-) & RMSE (m) & Bias (m) & Skill (-) & RMSE (m) & Bias (m) & Skill (-) \\
\hline Maximum & 0.08 & 0.08 & 0.97 & 0.17 & 0.15 & 0.79 & 0.07 & 0.06 & 0.94 \\
\hline Median & 0.04 & $<0.01$ & 0.83 & 0.09 & 0.07 & 0.40 & 0.03 & $<0.01$ & 0.73 \\
\hline Minimum & 0.02 & $<0.01$ & -4.17 & 0.05 & $<0.01$ & -3.81 & 0.01 & $<0.01$ & -0.54 \\
\hline
\end{tabular}
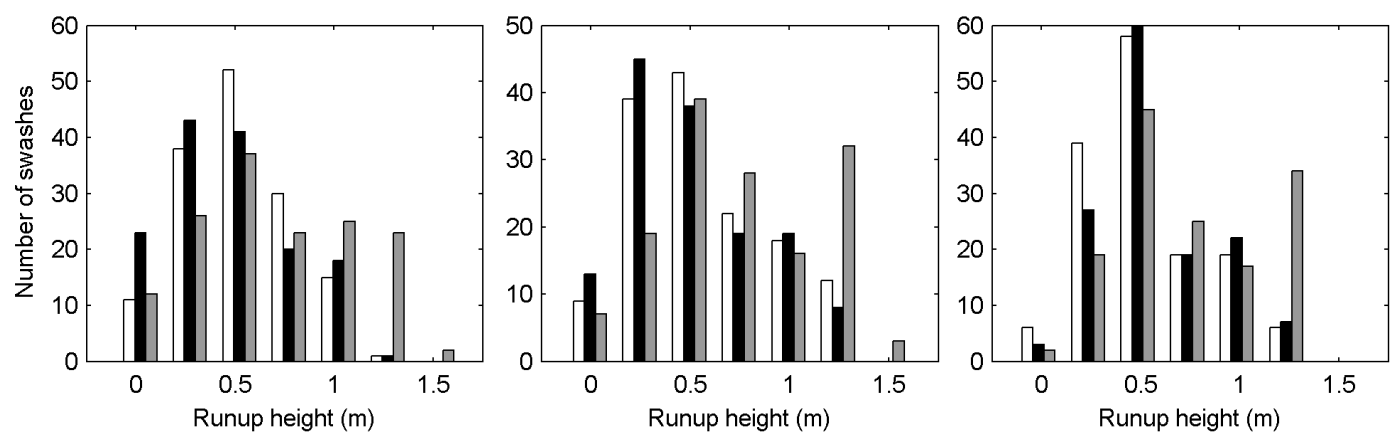

Figure 8. Histograms of runup levels extracted from ultrasonic bed level sensor measurements (white), modeled using the coupled groundwater-surface water model (black) and modeled using only the surface water model (grey), for Series BB1 (left), C1 (center) and C2 (right).

\begin{tabular}{|c|c|c|c|c|}
\hline Series & $\begin{array}{c}\text { Measured } \\
R_{2 \%} \\
\end{array}$ & $\begin{array}{c}\text { Coupled } \\
\text { model } R_{2 \%}\end{array}$ & $\begin{array}{l}\text { Modeled } R_{2 \%} \text { without } \\
\text { groundwater }\end{array}$ & Skill coupled model \\
\hline BB1 & $1.12 \mathrm{~m}$ & $1.11 \mathrm{~m}$ & $1.34 \mathrm{~m}$ & 0.99 \\
\hline $\mathrm{C} 1$ & $1.26 \mathrm{~m}$ & $1.28 \mathrm{~m}$ & $1.42 \mathrm{~m}$ & 0.98 \\
\hline $\mathrm{C} 2$ & $1.12 \mathrm{~m}$ & $1.15 \mathrm{~m}$ & $1.30 \mathrm{~m}$ & 0.97 \\
\hline
\end{tabular}

\section{Overwash simulation}

One 10-minute subseries of the BARDEX dataset in which overtopping and overwash took place (Series E10) is selected for simulation with the coupled groundwater-surface water model. As in the runup simulations, the modeled surface water elevation spectrum at the location of the shallow water pressure transducer is well resolved by the model (Figure 9).

The time series of measured and modeled groundwater head at four locations in the barrier are shown in Figure 10. As was the case for the runup simulations, the model shows considerable skill in reproducing the measured groundwater head variation in time and space, and the frequency shift of variance from high to low frequencies across the barrier. Similarly to Series BB1, the groundwater model consistently overpredicts the groundwater head at the back of the barrier (PT10 and PT13), which may be due to model artifacts or measurement data mismatch. Overall, the median RMSE for the groundwater head across all buried pressure transducers under the barrier is $0.08 \mathrm{~m}$ (Table 6), which is considered satisfactory for the purpose of this model. The groundwater model shows considerable skill $(>0.44)$ over an estimate of zero groundwater head change.

Since no data are available in the BARDEX dataset on individual wave overtopping discharges, swash depths measured by the array of 45 ultrasonic bed level sensors are used to analyze overtopping and overwash in the measurements and model. Figure 11 (left-hand panels) shows measured and modeled swash depths at three locations on the barrier. The model is shown to reproduce the decrease in swash depth and swash frequency with increasing distance across the barrier found in the measurements. The model has considerable statistical accuracy in predicting swash depths (Table 7), although it should be noted that inter-wave periods with zero swash depth significantly add these statistics. The majority of the error associated with the prediction of the overtopping swash depth occurs at the crest of the barrier, where the model appears to under-predict swash depths. 
The effect of coupling the groundwater model to the surface water model on the modeled overwash is analyzed by re-simulating series E10 with only the surface water model, in a manner similar to that carried out for the runup simulations. Figure 11 (right-hand panels) shows measured swash depths and modeled swash depths if groundwater interaction is not included. The figure shows that the surface water model without groundwater interaction overestimates the number of overtopping swashes, and to a lesser degree, the depth of the overtopping swashes. Table 8 lists the skill of the coupled groundwatersurface water model, relative to the surface water model without groundwater interaction, in predicting swash depth time series. The table shows that the incorporation of groundwater interaction improves the accuracy of the model at all locations (all skill values are positive), and the improvement increases in landward direction to the back of the barrier. These data suggest that the inclusion of groundwater interaction is essential to accurately simulate the hydrodynamics on the back-barrier during overtopping and overwash events, and ultimately overwash flow velocities, discharges and sediment transport fluxes.

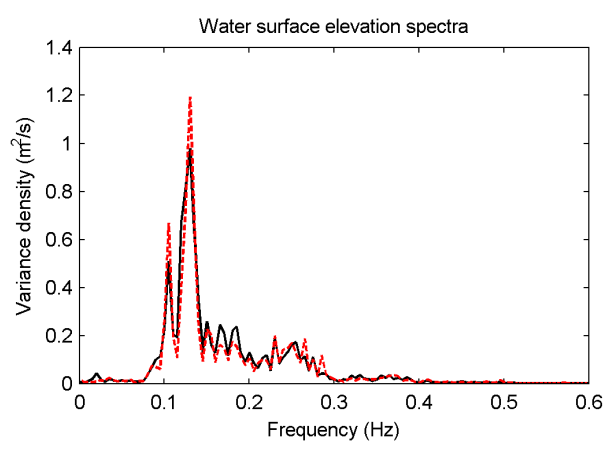

Figure 9. Measured (black) and modeled (red dashed) surface water elevation spectra at the location of the shallow water pressure transducer (cross-shore location $75 \mathrm{~m}$ ) for Series E10.
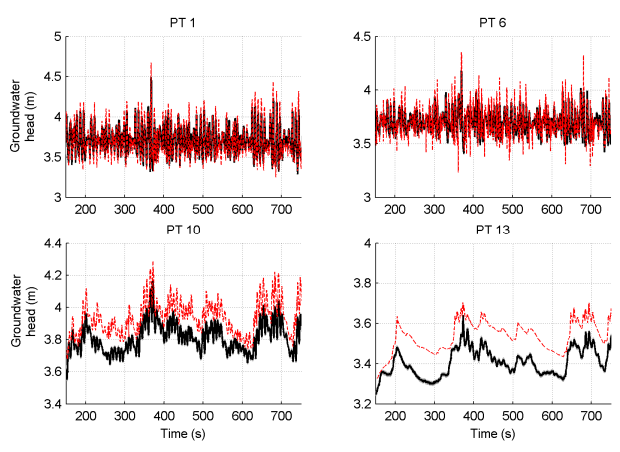

Figure 10. Measured (black) and modeled (red dashed) time series of groundwater head at four locations in the gravel barrier during series E10. Note that all locations correspond to those shown in Figure 5. Table 6. Error statistics of calibrated groundwater model for the groundwater head at all buried
pressure transducer measurement points during series E10. Skill is determined relative to no groundwater head change.

\begin{tabular}{|c|ccc|}
\hline & RMSE $(\mathrm{m})$ & Bias $(\mathrm{m})$ & Skill $(-)$ \\
\hline Maximum PT1-PT13 & 0.14 & -0.13 & 0.85 \\
Median PT1-PT13 & 0.08 & $<0.01$ & 0.74 \\
Minimum PT1-PT13 & 0.06 & $<0.01$ & 0.44 \\
\hline
\end{tabular}

Table 7. Error statistics for the swash depth at ultrasonic bed level sensors $\mathbf{3 5}$ - 45 during series E10. Skill is determined relative to no swash depth.

\begin{tabular}{|c|ccc|}
\hline & RMSE $(\mathrm{m})$ & Bias $(\mathrm{m})$ & Skill $(-)$ \\
\hline Maximum BLS35-45 & 0.03 & -0.01 & 0.75 \\
Median BLS35-45 & 0.02 & $<0.01$ & 0.58 \\
Minimum BLS35-45 & 0.01 & $<0.01$ & 0.27 \\
\hline
\end{tabular}

Table 8. Skill of simulated swash water depth at bed level sensors 35-45 in the coupled groundwater-surface water model, relative to simulated water depth in a model without groundwater interaction

\begin{tabular}{|ccccccccccc|}
\hline BLS35 & BLS36 & BLS37 & BLS38 & BLS39 & BLS40 & BLS41 & BLS42 & BLS43 & BLS44 & BLS45 \\
0.14 & 0.21 & 0.26 & 0.36 & 0.50 & 0.51 & 0.67 & 0.77 & 0.74 & 0.83 & 0.86 \\
\hline
\end{tabular}



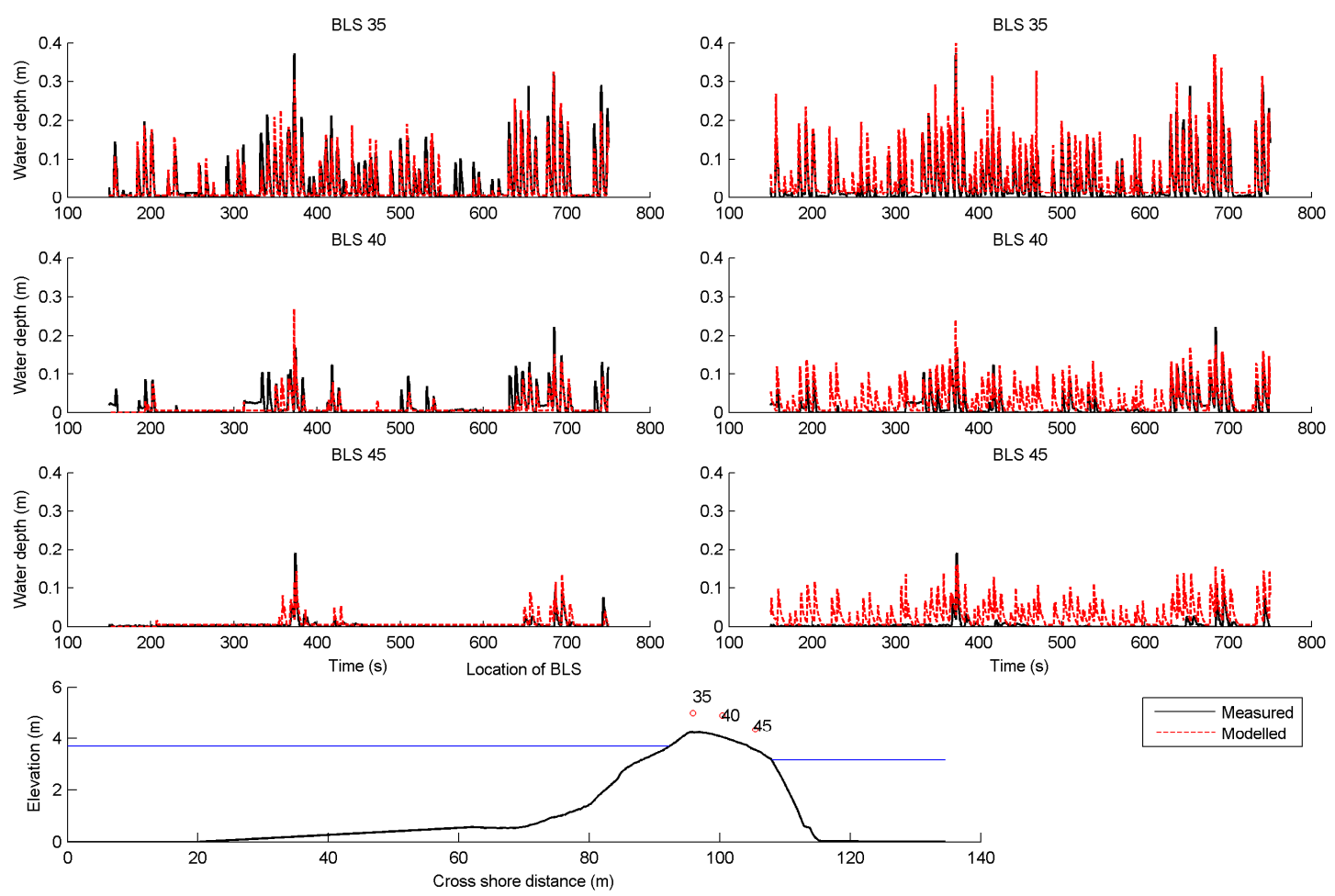

Figure 11. Time series of measured (black) and modeled (red dashed) swash depth caused by overtopping waves at three locations on the barrier. Left-hand panels correspond to the coupled groundwater-surface water model, right-hand panels to the surface water model without groundwater interaction. The locations of instruments, cross shore profile and still water levels are shown in the bottom panel.

\section{IMPLICATIONS FOR MODELING OVERWASH ON GRAVEL BARRIERS}

The results of Series E10 show that including groundwater interaction is important to accurately predict overtopping and overwash events. Since the coupled groundwater-surface water model allows water to infiltrate into the gravel as it overtops the barrier, the coupled model predicts fewer and less deep overwash events on the back barrier than the model with no groundwater interaction. This effect is reflected by the difference in overwash volumes across the barrier predicted by the models for Series E10 (Table 9). The results show that the difference in predicted overwash volumes ranges from a factor of 1.7 at the crest to 9.3 at the back barrier. The variation in overwash discharge in the coupled model imply that approximately $72 \%$ of the water overtopping the crest infiltrates into the bed before it reaches the back of the barrier.

Since infiltration has been shown to play an important role in the simulation of overwash events and volumes in the BARDEX series, it is relevant to study whether this is also true for barriers with less (or more) permeable sand and gravel matrices. In order to do so, Series E10 is re-simulated using the same initial and hydraulic boundary conditions as described in the previous section, but with values for the hydraulic conductivity $\left(K_{\text {lam }}\right)$ varying from $5 \cdot 10^{-4} \mathrm{~ms}^{-1}-5 \cdot 10^{-1} \mathrm{~ms}^{-1}$.

The results for these sensitivity simulations are shown in Figure 12, in which overwash volumes at the barrier crest and on the back barrier are shown relative to a case with no groundwater interaction. Clearly, the importance of infiltration increases with hydraulic conductivity. However, the figure also shows that infiltration effects start to become important in Series E10 at a hydraulic conductivity of approximately $1 \cdot 10^{-2} \mathrm{~ms}^{-1}$, which corresponds to typical values for fine gravel and well-sorted sandgravel mixtures (e.g. Coduto, 1999). Since the gravel barrier in Series E10 is relatively narrow, and infiltration is enhanced by increasing cross-barrier width, it is expected that in real-world cases infiltration may become important at even lower values of hydraulic conductivity.

From the considerations above, it would appear essential to include groundwater interaction when studying overwash on gravel barriers. In practical applications this requires relatively accurate estimates 
of the effective hydraulic conductivity of the barrier, which can be determined in-situ by permeability tests, or from detailed groundwater time series (e.g., Fetter, 1988; Austin et al., submitted). Since even half an order of magnitude error can lead to large disparities in predicted overwash volumes, sensitivity simulations, in combination with predicted and measured runup data, will remain indispensable for most real-world cases.

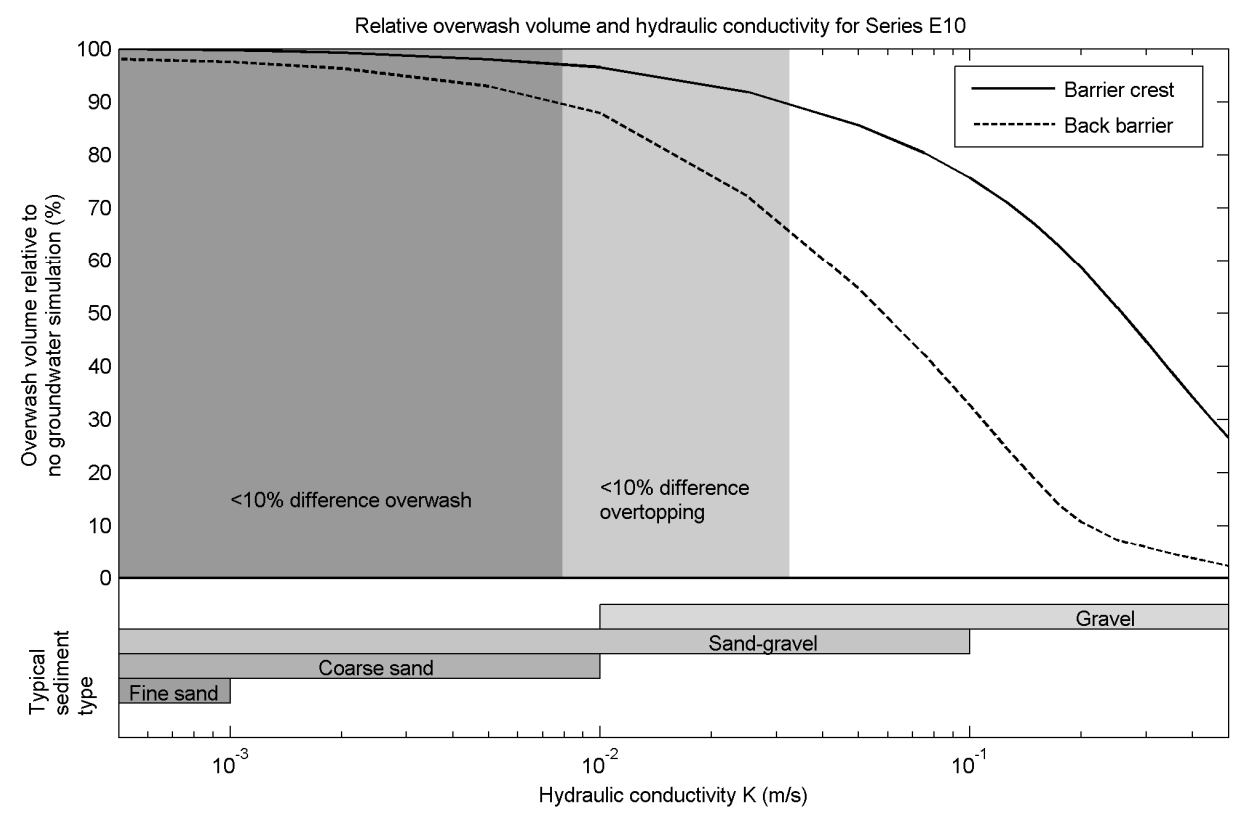

Figure 12. Relationship between hydraulic conductivity and relative overwash volumes at the barrier crest (BLS 35, solid line) and on the back barrier (BLS 45, dashed line) for Series E10. Shaded areas show less than $10 \%$ difference in overwash volume at the barrier crest (light grey) and on the back barrier (dark grey). Sediment types are estimates for given hydraulic conductivity (e.g., Coduto, 1999).

\begin{tabular}{|c|c|c|c|c|c|c|c|c|c|c|c|}
\hline & BLS35 & BLS36 & BLS37 & BLS38 & BLS39 & BLS40 & BLS41 & BLS42 & BLS43 & BLS44 & BLS45 \\
\hline Coupled model & 25.2 & 21.8 & 15.3 & 11.2 & 8.6 & 7.2 & 6.1 & 5.4 & 5.0 & 4.6 & 4.5 \\
\hline No groundwater & 41.9 & 41.9 & 41.9 & 41.9 & 41.9 & 41.9 & 41.9 & 41.8 & 41.8 & 41.8 & 41.8 \\
\hline
\end{tabular}

\section{ACKNOWLEDGMENTS}

The research in this study was funded by the Engineering and Physical Sciences Research Council (EPSRC; EP/H040056/1). In addition, RM and DR would like to acknowledge support given by Deltares (Strategic Research Projects 1204516 and 1202362) and by the European Community's Seventh Framework Programme under grant agreement no. 202798 (MICORE Project) for the funding of research leading to the results presented in this paper. Data reported here from the BARDEX experiment were collected in the Delta Flume (Netherlands) as part of the EU-funded BARDEX project (HYDRALAB III Contract no. 022441 (RII3), Barrier Dynamics Experiment).

\section{REFERENCES}

Austin, M.J.; Masselink, G.; McCall, R.T. and T.G. Poate. Submitted. Groundwater dynamics in coastal gravel barriers backed by freshwater lagoons and the potential for saline intrusion: two cases from the UK.

Bagnold, R.A. 1940. Beach formation by waves; some model-experiments in a wave tank. Journal of the ICE $, 15,27-52$.

Bradbury, A. 2000. Predicting breaching of shingle barrier beaches-recent advances to aid beach management. Proc. 35th Annual MAFF Conference of River and Coastal Engineers.

Buscombe, D. and G. Masselink. 2006. Concepts in gravel beach dynamics. Earth-Science Reviews, 79, $33-52$. 
CIRIA; CUR and CETMEF. 2007. The Rock Manual. The use of rock in hydraulic engineering (2nd edition), C683, CIRIA, London.

Coduto, D.P. 1999. Geotechnical Engineering Principles and Practices, Prentice-Hall, Englewood Cliffs, NJ.

Darcy, H. 1856. Les Fontaines Publiques de la Ville de Dijon, Technical report, Dalmont, Paris.

Ergun, S. 1952. Fluid flow through packed columns. Chemical Engineering Progress, 48, 88-94.

Fetter, C.W. 1988. Applied Hydrology. Merrill Publishing Company, p. 488.

Halford, K. 2000. Simulation and interpretation of borehole flowmeter results under laminar and turbulent flow conditions. Proc. 7th International Symposium on Logging for Minerals and Geotechnical Applications, Golden, Colorado. 157-168.

Harbaugh, A. 2005. MODFLOW-2005, the U.S. Geological Survey modular ground-water model - the Ground-Water Flow Process. U.S. Geological Survey Techniques and Methods. U.S. Geological Survey

Jamal, M.H., Simmonds, D.J., Magar, V. and S. Pan. 2010. Modelling infiltration on gravel beaches with an XBeach variant. Proc. 32nd International Conference on Coastal Engineering, Shanghai, China.

Jennings, R. and J. Shulmeister. 2002. A field based classification scheme for gravel beaches. Marine Geology, 186, 211-228.

Kuniansky, E.; Halford, K. and W. Shoemaker. 2008. Permeameter Data Verify New Turbulence Process for MODFLOW. Ground Water. 46(5), 768-771.

Mason, T. and T.T. Coates. 2001. Sediment Transport Processes on Mixed Beaches: A Review for Shoreline Management. Journal of Coastal Research. 17(3), 645-657.

McCall, R.T., Van Thiel de Vries, J.S.M., Plant, N., Van Dongeren, A.R., Roelvink, J.A., Thompson, D., and A.J.H.M. Reniers. 2010. Two-dimensional time dependent hurricane overwash and erosion modeling at Santa Rosa Island. Coastal Engineering. 57, 668-683.

Moses, C.A. and R.B.G. Williams. 2008. Artificial beach recharge: the South East England experience. Zeitschrift für Geomorphologie. Supplementband 52, 3, 107-123.

Orford, J.D. 1977. A proposed mechanism for storm beach sedimentation. Earth Surface Processes. 2: 381-400.

Packwood, A. 1983. The influence of beach porosity on wave uprush and backwash. Coastal Engineering. 7(1), 29-40.

Pedrozo-Acuña, A., Simmonds, D., Otta, A. and A. Chadwick. 2006. On the cross-shore profile change of gravel beaches. Coastal Engineering. 53(4), 335-347.

Powell, K.A. 1990. Predicting Short Term Profile response for shingle beaches. Report SR 219, HR Wallingford, Oxfordshire, UK.

Roelvink, J.A., Reniers, A.J.H.M., Van Dongeren, A.R., Van Thiel de Vries, J.S.M., McCall, R.T. and J. Lescinski. 2009. Modeling storm impacts on beaches, dunes and barrier islands. Coastal Engineering. 56, 1133-1152.

Shoemaker, W., Kuniansky, E., Birk, S., Bauer, S. and E. Swain. 2008. Documentation of a Conduit Flow Process (CFP) for MODFLOW-2005. U.S. Geological Survey Techniques and Methods, chapter A24, pp. 50.

Smit, P., Stelling, G., Roelvink, J.A., Van Thiel de Vries, J.S.M., McCall, R.T., Van Dongeren, A.P., Zwinkels, C. and R. Jacobs. 2010, XBeach: Non-hydrostatic model: Validation, verification and model description. Technical report, Delft University of Technology.

Turner, I.L., Russell, P.E. and T. Butt. 2008. Measurement of wave-by-wave bed-levels in the swash zone. Coastal Engineering. 55(12), 1237-1242.

Turner, I.L. and G. Masselink. 2012. Coastal gravel barrier hydrology - Observations from a prototypescale laboratory experiment (BARDEX). Coastal Engineering. 63, 13-22.

Ward, J. 1964. Turbulent flow in porous media. Journal of Hydraulic Division (ASCE) 90, 1-12.

Williams, J., Buscombe, D., Masselink, G., Turner, I.L. and C. Swinkels. 2012a, Barrier dynamics experiment (BARDEX): Aims, design and procedures. Coastal Engineering. 63(0), 3-12.

Williams, J., Ruiz de Alegría-Arzaburu, A., McCall, R.T. and Van Dongeren, A.P. 2012b. Modelling gravel barrier profile response to combined waves and tides using XBeach: Laboratory and field results. Coastal Engineering. 63, 62-80.

Zijlema, M., Stelling, G. and P. Smit. 2011. SWASH: An operational public domain code for simulating wave fields and rapidly varied flows in coastal waters. Coastal Engineering. 58(10), 992-1012. 